\title{
Local and regional scale biodiversity patterns of forest snail assemblages in Tuscany (central Italy)
}

\author{
A. Benocci ${ }^{1,3}$, G. Bacaro 2 and G. Manganelli ${ }^{1}$ \\ ${ }^{1}$ Department of Environment, Earth and Physical Sciences, University of Siena, Via P.A. Mattioli 4, \\ 53100 Siena, Italy \\ ${ }^{2}$ Department of Life Sciences, University of Trieste, Via L. Giorgieri 10, 34127 Trieste, Italy \\ ${ }^{3}$ Corresponding author. Email: andreaben76@libero.it; Tel: +39-0577-232901; Fax: +39-0577-232860
}

Keywords: CCA, Distance decay, Land snails, NMDS, Probability sampling, Tuscany.

\begin{abstract}
The land mollusc faunas of three forest areas of Tuscany (central Italy) were sampled to test the effect of geographical and environmental factors on the structure of biodiversity. A total of 60 sites were surveyed in the years 2009-2011, recording species richness and abundance of snails in $400 \mathrm{~m}^{2}$ plots randomly selected in beech and oak woods. Sampling strategy relied on a combination of visual search and litter analysis. Environmental variables (topsoil $\mathrm{pH}$ and altitude) and UTM coordinates were recorded to detect relationships with species richness and number of individuals per plot. Abundance data were analyzed using non-metric multidimensional scaling and canonical correspondence analysis; faunal similarity within and between areas was computed by the Bray Curtis index and snail assemblages of the two forest types were compared. A total of 55 species were recorded, with low values of local richness and abundance per site compared to other forest sites in central and northern Europe. Total richness was similar in the three areas, but composition and local richness varied significantly between them. Geographical factors explained the highest percentage of variance, while habitat type, altitude and $\mathrm{pH}$ only accounted for a minor part. Internal similarity was greater than between-area similarity in two out of three areas. Beech forests had richer and more heterogeneous faunas, but lower levels of abundance than oak woods. The results are discussed in terms of historical biogeography and local environmental conditions, and compared with those from similar surveys across Europe.
\end{abstract}

Nomenclature for snails: Manganelli et al. (1995).

Abbreviations: AM - Monte Amiata; AP - Alpi Apuane-Garfagnana; CA - Casentino-Alta Valle del Tevere.

\section{Introduction}

Many studies in the last two decades have focused on species diversity and composition of European land snail faunas, describing biodiversity patterns at local and regional scale. A few of them investigated snail assemblages of open habitats in the Aegean region (Cameron et al. 2000, 2003) while the majority focused on forest communities of central, northern and eastern Europe (Cameron and Pokryszko 2004, Pokryszko and Cameron 2005, Čejka et al. 2008, Cameron et al. 2006, 2010, 2011, Pokryszko et al. 2011). These faunas differ mainly in their origin: in peninsular Greece and the surrounding islands, snails survived Pleistocene glacial events in situ, whereas European malacofaunas of central and northern regions originated mainly from post-glacial recolonization from southern or extra-Mediterranean refugia (Hausdorf and Hennig 2003, Schmitt and Varga 2012). A different origin of recent snail associations in northern and southern Europe produced differing diversity patterns: much richer regional faunas and rapid distance decay in similarity in the Aegean region; regionally poor and rather uniform faunas in northern Europe (Cameron et al. 2000, Pokryszko and Cameron 2005, Cuttelod et al. 2011). Tuscany (central Italy) lies in an approximately intermediate position between the Aegean and the other regions investigated in these studies (Figure 1a): it belongs to the Mediterranean ecoregion, but its reliefs (Apennine and other mountain ranges) have a more continental climate (Selvi 1997) and host forest snail faunas which share several genera and species with central and northern Europe. Since there has been no research on the origin and biodiversity patterns of these assemblages, the study of species diversity and composition at local and regional scale is particularly challenging.

Italy hosts the largest number of continental molluscs in Europe after Greece, being a major hotspot for narrow-range endemics (Cuttelod et al. 2011), including forest-dwelling snails (Manganelli et al. 1995). Of the species of conservation concern investigated for the compilation of the European Red List of Non-marine Molluscs, more than half have insufficiently known populations (Cuttelod et al. 2011); in Italy, information is also lacking on the status, distribution and threats of most rare and decreasing species (Giusti et al. 2005). Thus, preliminary knowledge on diversity patterns at different spatial scales can not only provide interesting information on environmental factors, but also a useful tool for conservation issues. Forests of the Mediterranean basin are 

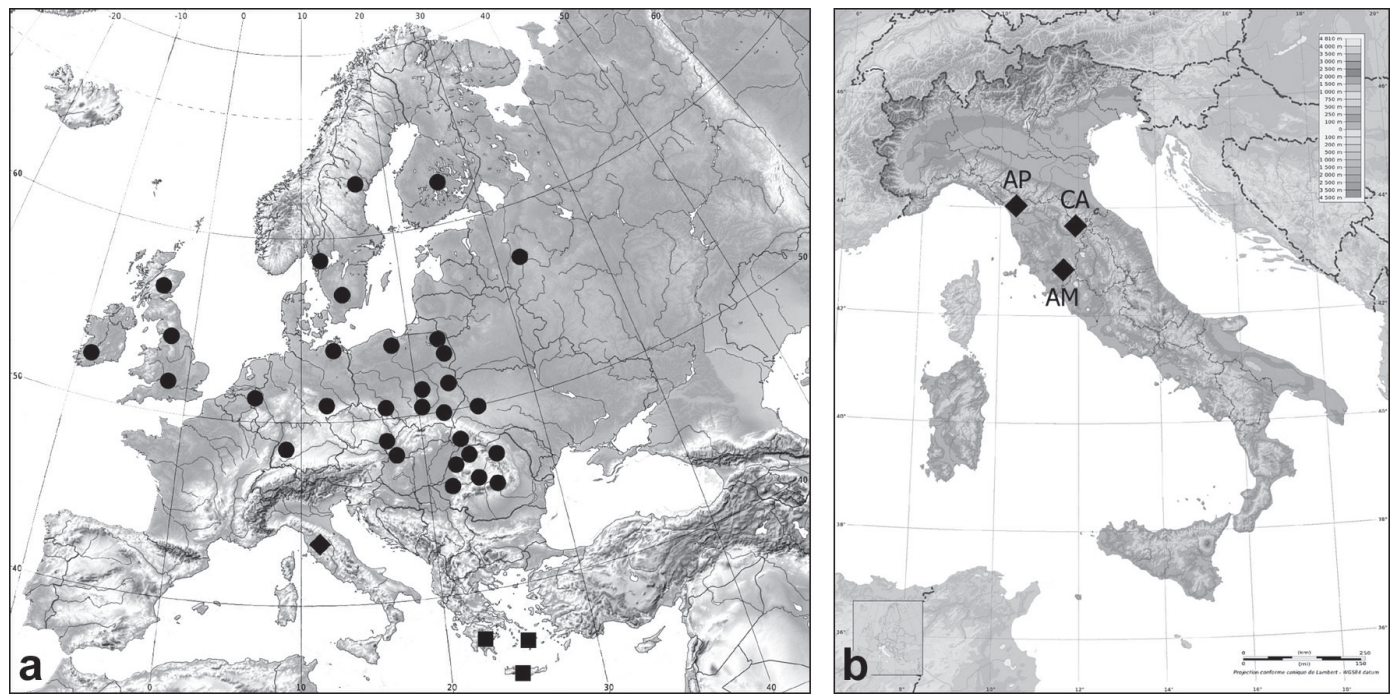

Figure 1. Position of the forests investigated in the present study (diamond) and in similar quantitative studies previously carried out in central and northern Europe (circles): only studies based on similar sampling methods were selected (for a list, see Table 5). The squares indicate the position of maquis and open habitat sites investigated for other studies (a). Position of the three study areas in Italy (b).

particularly sensitive to climate change effects, especially increased temperatures, modified rainfall patterns and soil properties (Resco de Dios et al. 2007), factors that can negatively affect the local survival of snails (Pearce and Paustian 2013); thus, describing their biocoenoses can provide valuable insights in monitoring and prevention programs, especially in protected areas. Ecological factors that shape terrestrial snail assemblages have been investigated in central and northern Europe for decades, focusing on single or combinations of environmental parameters (Valovirta 1968, Evans 1972, Martin and Sommer 2004, Horsák 2006, Kappes et al. 2006, Sulikowska-Drozd and Horsák 2007, among others) but such studies are almost completely lacking for Italian land snails (Giusti et al. 2005), except for a paper on acid woodland in the southern Alps (Bishop 1980).

Here we report a survey of snail assemblages in three forest areas of Tuscany (Figure 1b), carried out in two habitat types to test the effect of geographical and environmental factors on the structure of biodiversity: such questions have never been addressed before in Italy. Another innovative aspect of this research concerns the selection of plots: in previous studies focused on biodiversity patterns of European land snails, sampling sites were chosen ad hoc, whereas we opted for random selection. This and similar surveys to be carried out in other forest areas of Italy will help unveil the mechanisms underlying the present biodiversity patterns of land snails in temperate regions not subject to Pleistocene glaciations.

\section{Materials and methods}

Mollusc sampling was carried out in three forest areas of peninsular Italy: 1) Alpi Apuane-Garfagnana (AP) on the NW border of Tuscany; 2) Casentino-Alta Valle del Tevere (CA) on the NE border of Tuscany; 3) Monte Amiata (AM) in southern Tuscany (Figure 1b). These areas were chosen because of their position along a latitudinal gradient in the Apennine chain and their extensive forest cover with relatively undisturbed mesophilous beech woods and more thermophilous deciduous oak woods. The first area includes the southeastern portion of the Alpi Apuane mountain range (highest elevation $1859 \mathrm{~m}$ ) and the nearby Serchio River valley, characterized by partly calcareous and partly acid substrates and very moist climate due to proximity to the Tyrrhenian Sea; the second area includes the south-eastern portion of the Casentino (central-northern Apennines) and minor reliefs bordering the upper Tiber valley (highest elevation $1414 \mathrm{~m}$ ), characterized by mainly sandy, clayey and marly substrates and fresh, moist climate; Monte Amiata is an isolated massif $(1738 \mathrm{~m})$ originated by an extinct volcano, representing an "island" of oceanic climate in a sub-Mediterranean context: its upper portion consists of acid magmatic rocks, while the sedimentary basement consists mainly of clays and sands (Selvi 1997, Carmignani and Lazzarotto 2004, Provincia di Arezzo 2004, Garbari and Bedini 2006). In each area, forests are scattered from low hills to mountain tops in a range of environmental conditions (topsoil $\mathrm{pH}$, slope, exposure, plant cover and so on).

Two habitat types were chosen: beech woods (composed of almost monospecific stands of European beech, Fagus sylvatica L.) and deciduous oak woods (mainly composed of Quercus pubescens Willd. and Quercus cerris L.). A map of forest vegetation of Tuscany (Arrigoni et al. 1999) was used as cartographic basis for the selection of plots. In each area, a sampling square of $20 \mathrm{~km} \times 20 \mathrm{~km}$ was defined on the basis of suitable habitat: in each of the three $400 \mathrm{~km}^{2}$ squares, all available sites of beech and deciduous oak forests were identified and counted. Twenty sites for each area/habitat combination were then chosen randomly from all the available sites. The first ten were selected as sampling units, but some were discarded after a preliminary field survey, due to unsuitability of the habitat, human disturbance or accessibility problems; 
Table 1. Comparison of basic data (species richness, abundance and ranges) for the areas sampled in the present study.

\begin{tabular}{lcccc}
\hline & AP & CA & AM & Total \\
\hline Species richness & 34 & 33 & 35 & 55 \\
Mean richness per site and range & $10.3(3-21)$ & $11.8(7-17)$ & $11.3(7-15)$ & $11.1(3-21)$ \\
Abundance & 2898 & 5019 & 6604 & 14,521 \\
Mean abundance per site and range & $144.9(8-538)$ & $251.0(71-798)$ & $330.2(96-743)$ & $242.0(8-798)$ \\
\hline
\end{tabular}

in such cases, they were replaced with some of the other ten, making a total of 60 sites.

Samplings were conducted from fall 2009 to spring 2011. At each site, a square plot of $400 \mathrm{~m}^{2}$ was selected in order to avoid transitions to different habitats and forest patches disturbed by tree logging, recent fires or heavy human exploitation. All the plots were searched by a single person for two hours, collecting larger snails in all available microhabitats. At the end of each visual search session, 15 litres of litter and upper soil were collected, bagged, dried and then sorted in the laboratory, sieving the material with meshes of decreasing size (Cameron and Pokryszko 2005). The coarsest fractions were searched with the naked eye, while the finest ones were analyzed under a Wild M5A light microscope to detect microsnails and young specimens of all species. All live specimens and fresh shells were identified and counted. Slugs were not collected since the sampling method used is not suitable for complete inventories of this group of molluscs (Cameron and Pokryszko 2005).

The upper portion of soil was also used to obtain measures of $\mathrm{pH}$. The general method was US EPA method 9045/D (US EPA 2004), adapted to our samples by minor changes. Each sample was sieved with a $1 \mathrm{~mm}$ mesh, and then a solution was obtained by centrifuging $10 \mathrm{~g}$ of sieved material and $10 \mathrm{ml}$ of ultrapure water for 20 minutes at $3500 \mathrm{rpm}$. The filtered solution was measured using a $\mathrm{pH}$ meter (Orion model 420A).

The significance of differences in mean richness and abundance per site between the three areas and the two habitat types were checked by the Kruskal - Wallis test (Sokal and Rohlf 1987). Matrices of presence/absence data were used to develop rarefaction curves to test sampling efficiency. Sample-based curves (Gotelli and Colwell 2001) were produced for the three areas and the two habitat types. Dissimilarity levels between pairs of plots were quantified using the Bray Curtis Index (Bray and Curtis 1957). To limit the effect of dominant species, analyses were carried out with $\log$-transformed abundance data $(\log (\mathrm{x}+1))$. The general pattern of these assemblages was investigated by non-metric multidimensional scaling (NMDS, McCune and Grace 2002), linking variations in composition with environmental factors (forest type, altitude, soil $\mathrm{pH}$ ) and geography (UTM metric coordinates east and north). The significance of all the variables was then tested by canonical correspondence analysis (CCA: ter Braak 1986): each variable was standardized and transformed into a new one (scaled to zero mean and unit variance) to avoid artificially different weights of variables with extremely heterogeneous measurement scales and ranges of values. To highlight the effect of environmental factors in structuring biodiversity, regardless of the spatial position of plots, CCA was repeated as partial (conditioned) analysis after removing the effect of geographical variables (Oksanen et al. 2013). Significance levels were tested by ANOVA (9999 permutations, Oksanen et al. 2013). Mean values of dissimilarity within and between areas were then measured and NMDS was used to obtain graphic visualization of dissimilarity between areas and habitat types through convex hull spider-web diagrams. All analyses were carried out with the software R 2.13.0 (R Development Core Team 2009) and "vegan" package (Oksanen et al. 2013). Analyses were also performed on presence/absence data, using the Jaccard index (Jaccard 1912): in most cases these results added no information and have been omitted; in other cases they are provided as supplementary online material, as are CCA diagrams.

\section{Results}

\subsection{Species richness, abundance and sampling efficiency}

The sampling resulted in an inventory of 55 species and 14521 individuals of land snails (Table 1). Species richness per area was uniform and differences in mean richness per site were not significant (Kruskal - Wallis, $\chi^{2}=2.48, \mathrm{p}=0.286$ ): CA had slightly higher mean species richness and AP had the lowest. AP had the highest (21 species) and lowest (three species) local richness. Differences in abundance were statistically significant (Kruskal - Wallis, $\chi^{2}=14.09, \mathrm{p}=0.0009$ ): AM had the highest and AP the lowest mean abundance. AP also hosted the site with the lowest local abundance ( 8 individuals). $43.6 \%$ of the species were found in just one area (Appendix 1); the number of species represented by single individuals was quite high (9); the rarefaction curves for the three areas (Figure 2) did not level out but were much less steep than the random curve.

\subsection{Faunal similarities}

Plots from the same area tended to cluster together in the NMDS ordination (Figure 3), especially along the first axis: $\mathrm{AP}$ and $\mathrm{AM}$ at the two extremes, $\mathrm{CA}$ in an intermediate position. There was rather clear segregation between beech sites and oak sites in CA and especially in AM, but not in AP. The Shepard plot (Appendix 2) indicated a good correspondence between interpoint distances and the dissimilarities (narrow scatter of points).

Heterogeneity, obtained by comparing Bray Curtis dissimilarity index between pairs of plots, was lower within than between areas for CA and AM (Table 2). On the contrary, AP showed high within-area heterogeneity (lower than heterogeneity with respect to AM but higher than heterogeneity with respect to $\mathrm{CA}$ and total heterogeneity). Internal similarity of 
Table 2. Mean site-by-site values of the Bray Curtis index of dissimilarity within and between sampled areas.

\begin{tabular}{lccc}
\hline & AP & CA & AM \\
\hline AP & 0.6422 & 0.6208 & 0.6551 \\
CA & & 0.4673 & 0.5346 \\
AM & & & 0.4768 \\
\hline
\end{tabular}

Total dissimilarity (mean value of site-by-site comparison between all areas): 0.6276

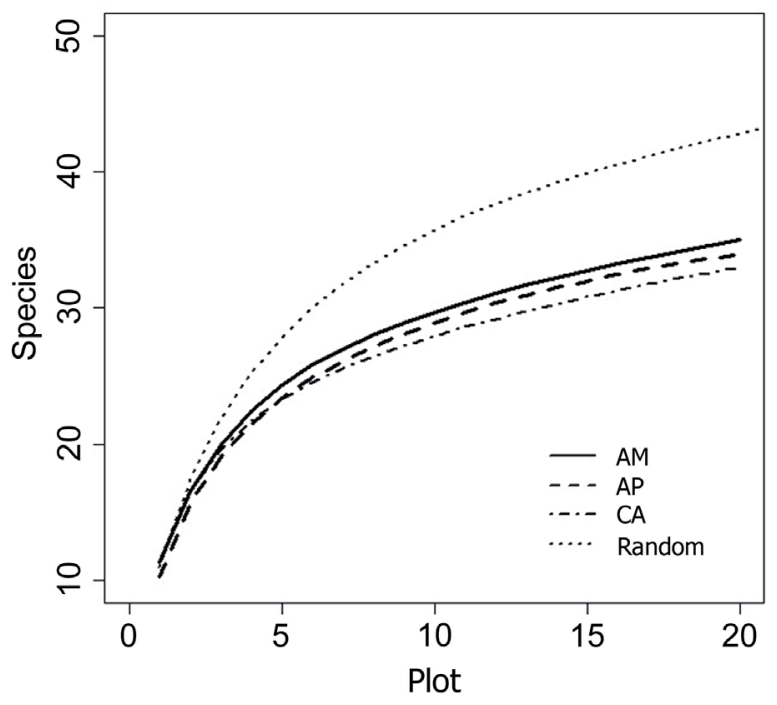

Figure 2. Rarefaction curves for the three study areas.

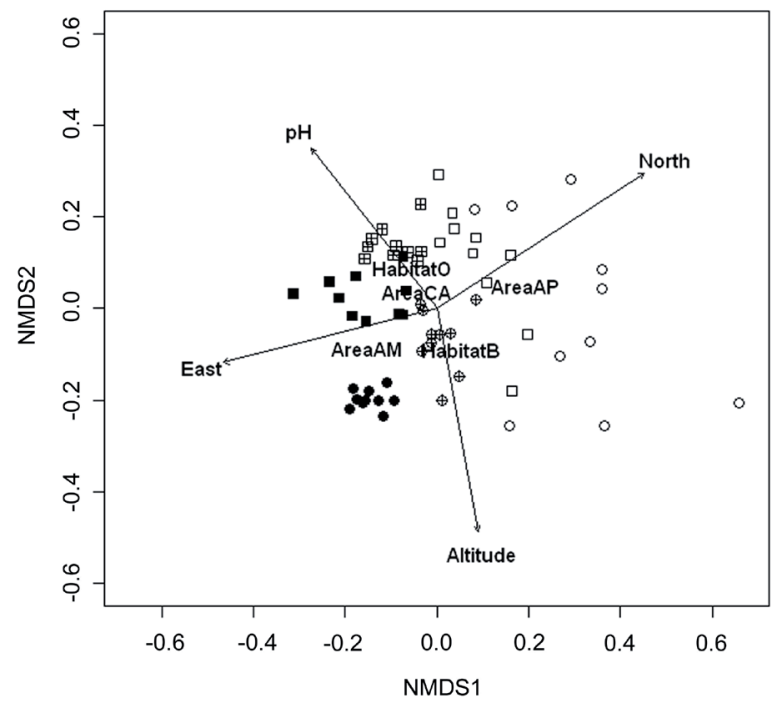

Figure 3. NMDS ordination of plots in the three study areas. Circles: beech woods; squares: oak woods; open symbols: AP; crossed symbols: CA; filled symbols: AM.

the three areas was higher for abundance than for presence/ absence data (Appendix 2).

Convex hull spider-web diagrams representing similarity between plots in the same area (Appendix 2) showed strong differentiation between faunas of the three areas, with only marginal overlap between CA and the other two (overlapping between all areas was much more evident for presence/ab-
Table 3. Comparison of basic data (species richness, abundance and ranges) for the two habitat types investigated in the present study.

\begin{tabular}{lccc}
\hline & Beech forests & Oak forests & Total \\
\hline Species richness & 47 & 35 & 55 \\
Mean richness & 11.2 & 11.0 & 11.1 \\
per site and range & $(3-21)$ & $(6-17)$ & $(3-21)$ \\
Abundance & 6548 & 7973 & 14,521 \\
Mean abundance & 218.3 & 265.8 & 242.0 \\
per site and range & $(8-798)$ & $(71-743)$ & $(8-798)$ \\
\hline
\end{tabular}

sence data); AP was again the most heterogeneous area both for abundance and presence/absence data.

\subsection{Variance analysis}

The overall pattern of CCA showed the highest percentage of variance explained by geographical factors.

The amount of variance explained by the first two axes was not very high $(12.59 \%$ and $9.57 \%$, respectively); both axes were significant $(\mathrm{p}=0.005)$, as were all variables $(\mathrm{p}=0.01$ for habitat and coordinates east and north; $\mathrm{p}=0.02$ for altitude; $\mathrm{p}=0.05$ for $\mathrm{pH}$ ). Unlike the others, the variable $\mathrm{pH}$ was significant only for analyses of abundance, but not for presence/absence data.

When spatial factors were excluded from the analysis, the role of two environmental factors became more evident: the first axis was related to altitude and habitat type, while the second axis was hard to interpret. The variable $\mathrm{pH}$ seemed to have relationships with both axes and a negative correlation with altitude. The amount of variance explained was lower for unconditioned $(13.74 \%)$ than for conditioned (18.07\%) variables: the first axis explained $11.70 \%$ of the variance, the second axis $3.18 \%$. Both axes were significant $(\mathrm{p}=0.005$ and $\mathrm{p}=0.015$, respectively), as were all variables $(\mathrm{p}=0.04$ for $\mathrm{pH}$; $\mathrm{p}=0.01$ for habitat and altitude).

\subsection{Habitat comparison}

Beech forests hosted a greater number of species (47 out of a total of 55) and tended to be more heterogeneous, having wider ranges for number of species and individuals per plot (Table 3). Oak forests were slightly poorer and more uniform in species richness and slightly richer in number of individuals. However, differences in species richness and abundance per site between the two habitat types were not significant $\left(\chi^{2}=0.002, \mathrm{p}=0.96\right.$ for species richness and $\chi^{2}=0.32, \mathrm{p}=0.57$ for abundance).

Rarefaction curves for the two habitat types (Figure 4a) were also very different: for oak forests the curve tended to flatten, whereas for beech forests it was still not stable, suggesting that a certain number of species may have been missed. The three areas, however, had different levels of heterogeneity per habitat: AP and CA (Figure 4b and 4c) had curves that followed the global scheme, while AM (Figure 4d) had very homogeneous beech forests (curve rapidly levelling off) and more heterogeneous oak forests. 
Table 4. Comparison of results (mean and total species richness and abundance of forest snails) found by previous authors in other regions of Europe and by us (only studies that used the same plot size and comparable sampling methods are included).

\begin{tabular}{|c|c|c|c|c|c|c|c|c|c|}
\hline Source & Area & $\begin{array}{l}\text { No. of } \\
\text { plots }\end{array}$ & Plot size & Visual search & Litter sampling & $\begin{array}{l}\text { Species } \\
\text { richness }\end{array}$ & $\begin{array}{l}\text { Mean richness } \\
\text { per site and } \\
\text { range }\end{array}$ & Abundance & $\begin{array}{c}\text { Mean } \\
\text { abundance } \\
\text { per site and } \\
\text { range }\end{array}$ \\
\hline Present study & $\begin{array}{l}\text { Tuscany (cen- } \\
\text { tral Italy) }\end{array}$ & 60 & $400 \mathrm{~m}^{2}$ & 1 person for $2 \mathrm{~h}$ & 151 of litter & 57 & $\begin{array}{r}11.1 \\
(3-21)\end{array}$ & 14,521 & $\begin{array}{r}242.0 \\
(8-798)\end{array}$ \\
\hline $\begin{array}{l}\text { Cameron and } \\
\text { Pokryszko (2004) }\end{array}$ & $\begin{array}{l}\text { Bialowieza } \\
\text { (Poland) }\end{array}$ & 17 & $400 \mathrm{~m}^{2}$ & 2 people for $1 \mathrm{~h}$ & 101 of litter & 45 & $\begin{array}{r}26.1 \\
(13-32)\end{array}$ & 4693 & $\begin{array}{r}276.1 \\
(126-725)\end{array}$ \\
\hline $\begin{array}{l}\text { Cameron et al. } \\
\text { (2006) }\end{array}$ & $\begin{array}{l}\text { Southern } \\
\text { England }\end{array}$ & 30 & $400 \mathrm{~m}^{2}$ & 2 people for $1 \mathrm{~h}$ & 101 of litter & 43 & $\begin{array}{r}27.6 \\
(22-32)\end{array}$ & 19,883 & $\begin{array}{r}662.8 \\
(378-1029)\end{array}$ \\
\hline $\begin{array}{l}\text { Cameron et al. } \\
\text { (2010) }\end{array}$ & Poland & 161 & $400 \mathrm{~m}^{2}$ & 2 people for $1 \mathrm{~h}$ & 10-20 1 of litter & 111 & $\begin{array}{r}27.2 \\
(13-43)\end{array}$ & 86,191 & $\begin{array}{r}535.3 \\
(126-2257)\end{array}$ \\
\hline $\begin{array}{l}\text { Cameron et al. } \\
\text { (2011) }\end{array}$ & $\begin{array}{l}\text { Transylvania } \\
\text { (Romania) }\end{array}$ & 43 & $400 \mathrm{~m}^{2}$ & $\begin{array}{l}4 \mathrm{~h} \text { (no of people } \\
\text { not specified) }\end{array}$ & 201 of litter & 83 & $\begin{array}{r}26.9 \\
(19-40)\end{array}$ & 17,715 & $\begin{array}{r}412.0 \\
(157-765)\end{array}$ \\
\hline $\begin{array}{l}\text { Pokryszko et al. } \\
\text { (2011) }\end{array}$ & $\begin{array}{l}\text { Georgian } \\
\text { Transcaucasia }\end{array}$ & 30 & $400 \mathrm{~m}^{2}$ & 5 person hours & 201 of litter & 90 & $\begin{array}{r}15.9 \\
(8-21)\end{array}$ & 6993 & $\begin{array}{r}233.1 \\
(60-530)\end{array}$ \\
\hline Cejka et al. (2008) & Slovakia & 42 & $400 \mathrm{~m}^{2}$ & 1 person for $1 \mathrm{~h}$ & $\begin{array}{l}0.25 \mathrm{~m}^{2} \text { of litter } \\
\text { twigs and soil }\end{array}$ & 41 & $\begin{array}{r}11.0 \\
(4-26)\end{array}$ & 10,970 & 261.2 \\
\hline
\end{tabular}
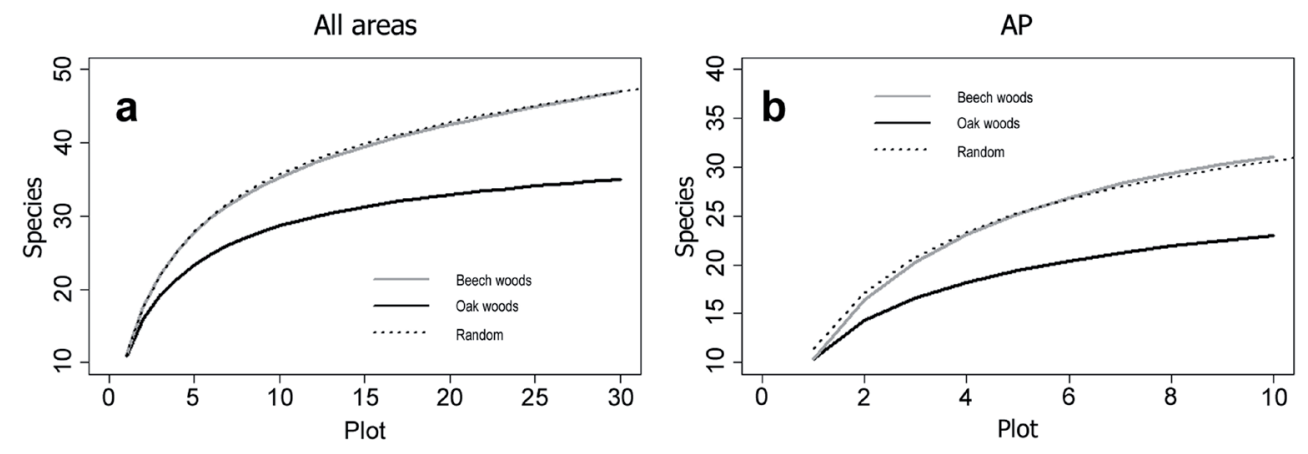

CA
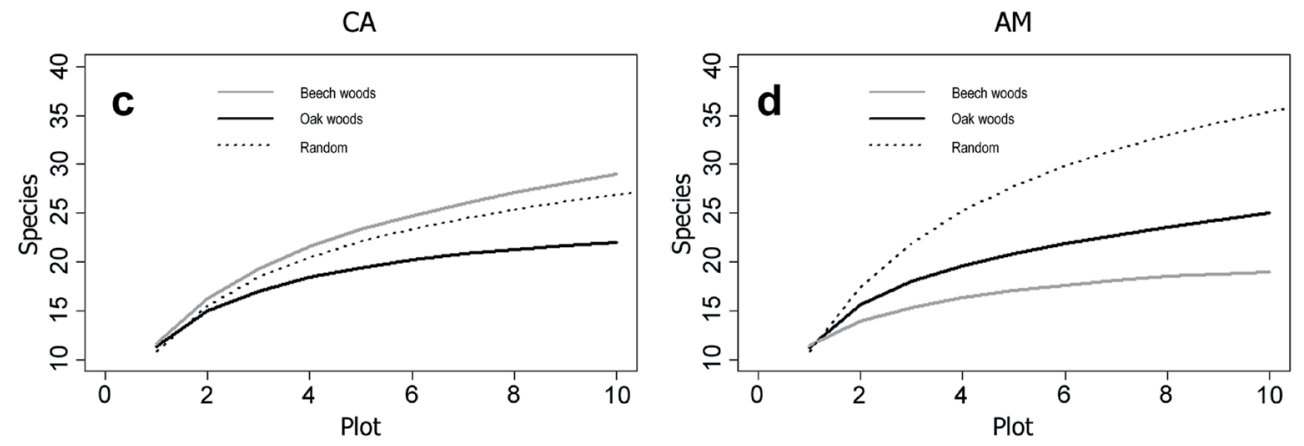

Figure 4. Rarefaction curves for the two habitat types. Total values for the three areas (a) and for single areas: AP (b), CA (c) and AM (d).

Spider diagrams representing similarity between plots of the same habitat (Figure 5) showed higher heterogeneity for snail faunas of beech forests and a high degree of overlap between faunas of the two vegetation types (overlap was even higher for presence/absence data).

\section{Discussion}

\subsection{Species richness, abundance and sampling efficiency}

The three areas showed low levels of species richness at regional and local scale, compared to similar forests of central, northern and eastern Europe (Table 4). At regional scale, richness is influenced by the size of the area (Rosenzweig 1995), which, in the present study, was smaller than those investigated in other surveys (Cameron et al. 2010, 2011, Pokryszko et al. 2011). Lower regional richness has indeed been found in areas smaller than Tuscany (Cameron and Pokryszko 2004, Cameron et al. 2006, Čejka et al. 2008), whereas for local richness, no other area had such low numbers of species per site, except Danubian floodplain forests, which are regularly flooded (Čejka et al. 2008). There are several reasons that may account for such low species numbers. First, the randomized sampling used may partly account for failure to find rare 


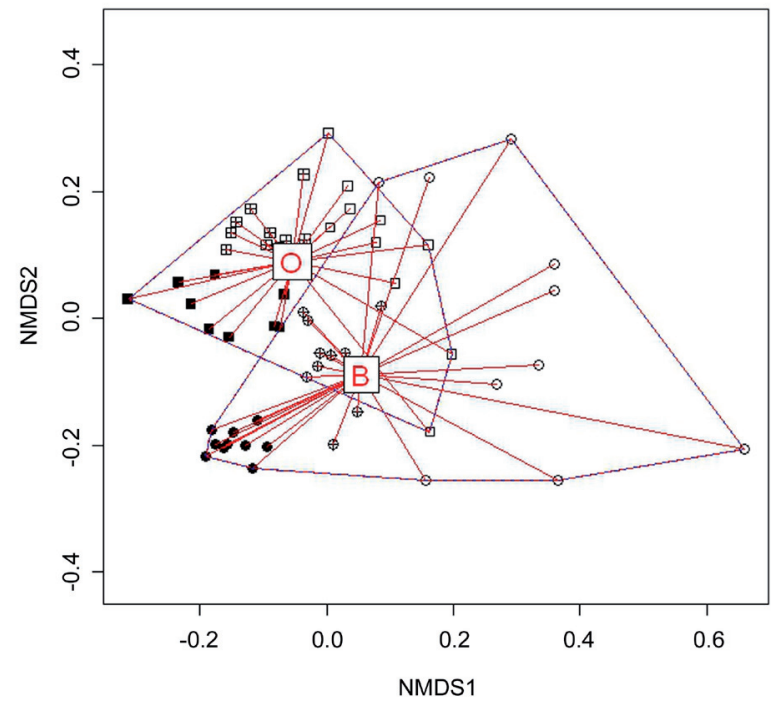

Figure 5. Spider diagrams representing faunal similarities between the two habitat types. Open symbols: AP; crossed symbols: CA; filled symbols: AM. O: oak forest, B: beech forest.

species in certain sites or even in whole areas. In all the other studies, sample sites were selected ad hoc, choosing rich forest patches that presumably hosted a large array of species and great numbers of specimens. On the contrary, our plots also included very poor sites (e.g., beech forests on very acid substrates or steep slopes). This may also have affected local abundance: our forests are also poorer in mean numbers of specimens per site than other areas, the only exception being Georgian forests, where snail fauna is reportedly impoverished by management and unfavourable climatic and environmental conditions (Pokryszko et al. 2011). Nevertheless, rarefaction curves for the three areas did not rise steeply with increased sample size, suggesting that the number of missed species is not very high: this is confirmed by the fact that most species known to occur in the three areas, on the basis of previous knowledge and unpublished field research, were recorded during this survey. Indeed, the high number of singletons is mainly due to detection of species which are not strictly associated to forests, present in the plots by chance (e.g., calciphile rock-dwelling snails found in calcareous outcrops within forests, or meadow species surviving in sites that were once logged). Cameron and Pokryszko (2005) state that randomized sampling is not suitable for land snails, because these animals tend to have clustered distributions, and areas or microhabitats with the highest levels of specific diversity and abundance can easily be missed by this sampling procedure, exaggerating differences between sites. These authors therefore recommend preferential sampling to selectively increase the probability of encountering rare species. No one has ever compared the efficiency of randomized and preferential sampling for land snails; on the contrary, botanists have long discussed the topic for plant censuses. After comparing phytosociological datasets obtained by different methods in the same areas, most recent authors (e.g., Diekmann et al. 2007) agree that preferential sampling is hardly suitable for inferential statistical tests, since it is not based on representa- tive samples. Moreover, these authors suggest to use results based on probabilistic sampling to extend to wider areas species richness estimates since, in this way, known confidence intervals can be easily and correctly calculated. This is why we adopted a sampling strategy based on random selection of plots, even if we were aware of its limits, especially for diverse and heterogeneous regions.

Another factor explaining the low values of regional and local richness may be the restricted pool of forest snail species in peninsular Italy, possibly due to historical processes. There have been no detailed studies on the origin of Italian malacocoenoses, but it is known that faunas with W-Palaearctic and European affinities reached Italy from northern Europe between the Pliocene and the end of the Pleistocene (Ruffo and Stoch 2006). Some snails with northern affinities may never have reached the Apennine area because of the climatic barrier represented by the Po Plain: drier and warmer conditions south of this limit would have prevented markedly hygrophilous and mesophilous species from spreading to the Apennines (Sacchi 1963). Furthermore, a marked increase in temperatures along the Apennine chain after the last glacial age caused local contraction of the ranges of cold climate faunas, which remained confined to the highest mountains: forest snails with northern affinities once present in peninsular Italy may have disappeared at this time, withdrawing to cooler and moister areas north of the Po Plain (Ruffo and Stoch 2006).

Finally, previous studies also investigated lowland or floodplain forests (Cameron and Pokryszko 2004, Cameron et al. 2006, Čejka et al. 2008), some of which host several wetland species, absent or rare in the hilly or montane forests studied by us.

\subsection{Faunal similarities}

Despite very similar values of species richness in the three areas, species composition varied greatly and inter-area similarity was quite low. In Poland, Cameron et al. (2010) found much greater heterogeneity in highland than in lowland forests. Thus we might expect altitude to be an important factor in the variation of species composition in our forests, since they are all located in montane areas. Similarity was higher within than between areas for CA and AM, revealing clear geographical differentiation of the two areas. On the contrary, AP displayed very high internal differentiation, indicating an important role of local environmental factors. AP is indeed a very heterogeneous area, with extremely uneven morphology and lithology and sharp climatic differentiation between internal and coastal mountainsides (Garbari and Bedini 2006). It also contains very poor plots on non-eutrophic forests, which usually have more variable compositions and high heterogeneity levels (Pokryszko and Cameron 2005). At the other extreme, AM has very homogeneous fauna, probably because it is an isolated massif with continuous belts of deciduous woods from the base to the summit of the volcanic cone (Selvi 1997).

Internal similarity of the three areas was higher for abundance than for presence/absence: this seems to suggest that 
geographical position not only affects the distribution, but also the differential success of species common to two or more regions. Indeed, spider diagrams showed much more overlap between different areas for presence/absence data than for abundances.

Heterogeneity between areas increased with relative distance: the highest was found between AP and AM, the most distant from each other. The spider diagrams did not show any overlap between the two areas, whereas both partly overlapped with CA, intermediate between the two. Indeed, areas closer to each other shared more species than areas far apart (Appendix 1). Variations in species composition may be partly explained by biogeographical factors, such as distance from source fauna. For instance, the geographical position of AP not far from the Alpine chain facilitated the spread of northern species, which here encounter the southern limit of their range (e.g., Renea elegantissima, Platyla similis, Cochlodina fimbriata; Manganelli et al. 1995) and are therefore absent from CA and AM. Not surprisingly, AP had the highest percentage of unique species: $38 \%$ compared to $12 \%$ for CA and $20 \%$ for AM. Other species, such as Vitrinobrachium baccettii and Platyla stussineri, occur in northern Tuscany (AP and CA) but are absent from southern Tuscany (AM). A loss of similarity with increasing distance between areas is also probably due to geographical barriers which, in the study areas, are represented by major valleys, and at least for AM, surrounding lowland areas with sub-Mediterranean climate (Selvi 1997). For other soil invertebrates, the Arno Valley has prevented many Apennine taxa from penetrating south of the river (Taiti and Ferrara 1989), and the same could apply to the Serchio, which almost isolates AP.

\subsection{Variance analysis}

Most variance was explained by the factor "area". Significantly, the relative position of plots along the axes of the CCA reflected real geography: AP and AM at two extremes and CA in an intermediate position. The explanatory role of north coordinates, and to a lesser extent east coordinates, is partly linked to a sharp "Apennine" gradient in Italian faunas: species with northern affinities generally show a gradual decrease from $\mathrm{N}$ to $\mathrm{S}$, following the direction of the Apennine chain, which is orientated NW-SE (Ruffo and Stoch 2006). Vegetation type was also important, as shown by the clear segregation between beech and oak sites. However, the global contribution of measured environmental factors (altitude, vegetation type and $\mathrm{pH}$ ) was limited, even excluding the effect of geographical variables: other factors that contribute to shaping diversity patterns were apparently not traced by us. For example, Evans (1972) suggested that the gross structure of the environment (habitat type) is not very important for small litter species, while other variables, such as slope, herbaceous plant cover, shade and certain soil properties, may account for their presence in a particular site. Such species actually seem to show no close association with forest habitats, sometimes preferring tall grasslands that provide a minimum of shade and moist litter and avoiding forests characterized by sparse tree cover, no grass and steep slopes (where litter is scarce and soil retains little moisture). This could explain, for example, the paucity of litter snails in several plots: the poorest sites in AP were in fact those characterized by beech woods on steep slopes. Martin and Sommer (2004), Müller et al. (2005) and Kappes et al. (2006) confirmed the importance of soil moisture, herbaceous cover and slope aspect, respectively, in shaping forest snail assemblages.

Notably, pH was significant for abundance data but not for presence/absence. $\mathrm{pH}$ may significantly affect abundance but not occurrence of species because of the differential rate of shell erosion in acid and non-acid soils: since shells are eroded more rapidly at low pH (Evans 1972, Juřičková et al. 2008), plots on very acid substrates conserve fewer fresh empty shells, which in our case were counted. Kappes et al. (2006) also found that soil $\mathrm{pH}$ was positively correlated with snail abundance but not with species richness. On the contrary, Valovirta (1968) and Juřičková et al. (2008) recorded lower species numbers in acid plots. Calcium-rich sites (that usually have high $\mathrm{pH}$ ) are in general richer both in number of individuals and species (Pokryszko and Cameron 2005, Martin and Sommer 2004, Horsák 2006, Sulikowska-Drozd and Horsák 2007, Juřičková et al. 2008), thus pH would also be expected to influence species richness in limestone sites. In our case, however, even plots on calcareous substrates had slightly acid $\mathrm{pH}$ (never higher than 6.71) and this parameter is probably not closely correlated with the amount of calcium. Indeed, Juřičková et al. (2008) only found a positive correlation between topsoil $\mathrm{pH}$ and calcium content in one out of two sets of 20 quadrats in the Czech Republic and concluded that when calcium is not abundant, $\mathrm{pH}$ is an inadequate estimator of its availability. They hypothesized that in many cases soil moisture or other factors could have a greater role than chemical properties of soil and litter in determining local species richness and abundance of forest snails. Martin and Sommer (2004) actually reported a major influence of soil moisture on snail assemblages in German forests, while Müller et al. (2005), Kappes et al. (2006) and Sólymos et al. (2009) highlighted the importance of dead wood and/or litter thickness as factors increasing species richness and densities of snails in central European forests. The parameter altitude does not always show a clear trend or uniform patterns for land snails: some studies revealed peaks of species richness at intermediate altitudes, while others found a steady decrease with increasing elevation (Sulikowska-Drozd and Horsák 2007).

\subsection{Habitat comparison}

The vegetation of deciduous oak woods analyzed wasmore diverse than the beech woods (Mondino and Bernetti 1998); moreover, beech woods are known to host rather uniform malacocoenoses throughout the Italian peninsula (Giusti et al. 1985, Minelli 2006). Notwithstanding this, our study revealed more heterogeneous snail faunas in beech woods than oak woods in two out of three areas (CA and AP), and spider diagrams representing levels of similarity between plots of the same habitat confirmed this trend. On the average, beech woods were regionally and locally richer in species than oak 
woods, although they showed lower mean abundances. This could be due to many species that occurred in low numbers with scattered distributions. During our survey many of these rare taxa were only found in beech woods, and this could be due to historical rather than environmental factors. Montane beech woods have generally been subject to less human disturbance than submontane oak or mixed forests, as a consequence of their limited accessibility. Higher percentages of undisturbed habitat may have preserved certain rare snails in beech woods, while in other forest types at lower altitudes these snails have disappeared due to human interference. Although many species can tolerate a moderate amount of disturbance, the richest European faunas at local level are normally reported from relatively unexploited montane forests (Cameron and Pokryszko 2004). Furthermore, various snail species which are normally found in lowland and submontane woods can in many cases spread to beech woods in search of favourable temperature and humidity conditions and join a pool of more mesophilous species apparently linked to cool moist beech woods, thus increasing the richness of this forest type (Giusti et al. 1985). It is noteworthy that almost all the species found in oak woods were also recorded in beech woods, and most of those that occur only in the former are not typical forest snails.

With regard to AM, the pattern was different from those of the other two areas, with beech woods poorer and more uniform in composition than oak woods. This is probably due to the geological nature of this area. Beech woods in AM are restricted to the upper portion of the volcanic cone. Their isolation on an unfavourable acid substrate probably caused these communities to become rather uniform and impoverished versions of the typical assemblages found in other beech woods of Tuscany.

Acknowledgements. We thank Dr. R. Cameron (Sheffield, UK) and T. Caruso (Belfast, UK) for their precious help in defining a sampling strategy. We also thank Prof. F. Giusti (Siena, Italy) for discussion and criticism. The topics discussed in this paper are part of the contents of a $\mathrm{PhD}$ thesis (A. B.) defended at Siena University on March 14th 2013.

\section{References}

Arrigoni, P.V., M. Raffaelli, M. Rizzotto, P.L. Di Tommaso, U. Miniati, B. Foggi, F. Selvi, L. Lombardi, D. Viciani, E. Menicagli, R. Benesperi, S. Benucci, G. Ferretti and P.E. Tomei. 1999. Regione Toscana. Carta della vegetazione forestale. Regione Toscana, serie Boschi e Macchie di Toscana. Selca, Florence.

Bishop, M.J. 1980. The Mollusca of acid woodland in the Italian province of Novara. J. Conchol. 30: 181-188.

Bray, J. and J. Curtis. 1957. An ordination of the upland forest communities of Southern Wisconsin. Ecol. Monogr. 27: 325-349.

Cameron, R.A.D., M. Mylonas, K. Triantis, A. Parmakelis and K. Vardinoyannis. 2003. Land-snail diversity in a square kilometre of Cretan maquis: modest species richness, high density and local homogeneity. J. Mollusc. Stud. 69: 93-99.

Cameron, R.A.D., M. Mylonas and K. Vardinoyannis. 2000. Local and regional diversity in some Aegean land snail faunas. $J$. Mollusc. Stud. 66: 131-142.
Cameron, R.A.D. and B.M. Pokryszko. 2004. Land mollusc faunas of Bialowieza Forest (Poland), and the character and survival of forest faunas in the North European plain. J. Mollusc. Stud. 70: 149-164.

Cameron, R.A.D. and B.M. Pokryszko. 2005. Estimating the species richness and composition of land mollusc communities: problems, consequences and practical advice. J. Conchol. 38 : 529547.

Cameron, R.A.D., B.M.Pokryszko and D.C. Horsák. 2010. Land snail faunas in Polish forests: patterns of richness and composition in a post-glacial landscape. Malacologia 53: 77-135.

Cameron, R.A.D., B.M. Pokryszko, D.C. Horsák, I. Sirbu and V. Gheoca. 2011. Forest snail faunas from Transylvania (Romania) and their relationship to the faunas of Central and Northern Europe. Biol. J. Linnean Soc. 104: 471-479.

Cameron, R.A.D., B.M. Pokryszko and D.C. Long. 2006. Snail faunas in Southern English calcareous woodlands: rich and uniform, but geographically differentiated. J. Conchol. 39: 13-39.

Carmignani L. and A. Lazzarotto. 2004. Carta geologica della Toscana. Università di Siena, Dipartimento di Scienze della Terra, Siena. Regione Toscana, Direzione regionale politiche territoriali e ambientali, Servizio geologico, Florence.

Čejka, T., M. Horsák and D. Némethová. 2008. The composition and richness of Danubian floodplain forest land snail faunas in relation to forest type and flood frequency. J. Mollusc. Stud. 74: 37-45.

Cuttelod, A., M. Seddon and E. Neubert. 2011. European Red List of Non-marine Molluscs. Publications Office of the European Union, Luxembourg. https://portals.iucn.org/library/efiles/ documents/RL-4-014.pdf

Diekmann, M., A. Kühne and M. Isermann. 2007. Random vs. nonrandom sampling: effects on patterns of species abundance, species richness and vegetation-environment relationships. Folia Geobot. 42: 179-190.

Evans, J.G. 1972. Land Snails in Archaeology. Seminar Press, London \& New York.

Garbari, F. and G. Bedini. 2006. The flora of the Apuan Alps (Tuscany, Italy): survey of biosystematics investigations. Willdenowia 36: 149-155.

Giusti, F., L. Castagnolo and G. Manganelli. 1985. La fauna malacologica delle faggete italiane: brevi cenni di ecologia, elenco delle specie e chiavi per il riconoscimento dei generi e delle entità più comuni. Boll. Malacol. 21(5-6): 69-144.

Giusti, F., G. Manganelli and S. Cianfanelli. 2005. Molluschi. In: C. Blasi, L. Boitani, S. La Posta, F. Manes and M. Marchetti (eds.), Stato della biodiversità in Italia. Contributo alla strategia nazionale per la biodiversità. Palombi, Rome. pp. 246-248.

Gotelli, N.J. and R.K. Colwell. 2001. Quantifying biodiversity: procedures and pitfalls in the measurement and comparison of species richness. Ecol. Lett. 4: 379-391.

Hausdorf, B. and C. Hennig. 2003. Nestedness of north-west European land snail ranges as a consequence of differential immigration from Pleistocene glacial refuges. Oecologia 135: 102109.

Horsák, M. 2006. Mollusc community patterns and species response curves along a mineral richness gradient: a case study in fens. $J$. Biogeography 33: 98-107.

Jaccard, P. 1912. The distribution of the flora in the alpine zone. New Phytol. 11: 37-50.

Juřičková, L., M. Horsák, R. Cameron, K. Hylander, A. Míkovcová, J.Č. Hlavác and J. Rohovec. 2008. Land snail distribution pat- 
terns within a site: the role of different calcium sources. Eur. $J$. Soil Biol. 44: 172-179.

Kappes, H., W. Topp, P. Zach and J. Kulfan. 2006. Coarse woody debris, soil properties and snails (Mollusca: Gastropoda) in European primeval forests of different environmental conditions. Eur. J. Soil Biol .42: 169-146.

Manganelli, G., M. Bodon, L. Favilli and F. Giusti. 1995. Gastropoda Pulmonata. In: A. Minelli, S. Ruffo and S. La Posta (eds.), Checklist delle specie della fauna d'Italia, 16. Edizioni Calderini, Bologna, pp 1-60.

Martin, K. and M. Sommer. 2004. Relationships between land snail assemblage patterns and soil properties in temperate-humid forest ecosystems. J. Biogeogr. 31: 531-545.

McCune, B. and J.B. Grace. 2002. Analysis of Ecological Communities. MjM Software Design, Gleneden Beach.

Minelli, A. (ed.). 2006. Beech forests of the Apennines: new populations and relicts of a continental forest. Quaderni Habitat 15. Ministero dell'Ambiente e della Tutela del Territorio - Museo Friulano di Storia Naturale, Rome and Udine.

Mondino, G.P. and G. Bernetti (eds.). 1998. I tipi forestali. Boschi e macchie di Toscana. Regione Toscana, Florence.

Müller, J., C. Strätz and T. Hothorn. 2005. Habitat factors for land snails in European beech forests with a special focus on coarse woody debris. Eur. J. Forest Res. 124: 233-242.

Oksanen, J., F.G. Blanchet, R. Kindt, P. Legendre, P.R. Minchin, R.B. O'Hara, G.L. Simpson, P. Solymos, M.H.H. Stevens and H. Wagner. 2013. vegan: Community Ecology Package. R package version 2.0-10 http://CRAN.R-project.org/package=vegan Accessed 20 June 2014.

Pearce T.A. and Paustian M.E. 2013. Are temperate land snails susceptible to climate change through reduced altitudinal ranges? A Pennsylvania example. Am. Malacol. Bull. 31: 213-224.

Pokryszko, B.M. and R.A.D. Cameron. 2005. Geographical variation in the composition and richness of forest snail faunas in northern Europe. Rec. West. Aust. Mus. Supplement 68: 115-132.

Pokryszko, B.M., R.A.D. Cameron, L. Mumladze and D. Tarkhnishvili. 2011. Forest snail faunas from Georgian Transcaucasia: patterns of diversity in a Pleistocene refugium. Biol. J. Linnean Soc. 102: 239-250.

Provincia di Arezzo. 2004. Aree protette della Provincia di Arezzo. Guida naturalistica con notizie storiche e percorsi di visita. Le Balze, Montepulciano (SI).

R Development Core Team. 2009. R: A language and environment for statistical computing. R Foundation for Statistical Computing, Vienna.

Resco de Dios, V., C. Fischer and C. Colinas. 2007. Climate change effects on Mediterranean forests and preventive measures. New Forest 33: 29-40.

Rosenzweig, M.L. 1995. Species Diversity in Space and Time. Cambridge University Press, Cambridge.
Ruffo, S. and F. Stoch (eds). 2006. Checklist and distribution of the Italian fauna. Memorie del Museo Civico di Storia Naturale di Verona, $2^{a}$ serie, Sezione Scienze della Vita 17, with cd-rom.

Sacchi, C.F. 1963. Origini ed evoluzione della malacofauna appenninica meridionale. Annuario dell'Istituto e Museo di Zoologia della Università di Napoli 15(7): 1-86.

Schmitt, T. and Z. Varga. 2012. Extra-Mediterranean refugia: The rule and not the exception? Frontiers in Zoology 9: 22.

Selvi, F. 1997. Rare plants on Mount Amiata, Italy: vulnerability to extinction on an ecological "island". Biol. Cons. 81: 257-266.

Sokal, R.R. and F.J. Rohlf. 1987. Introduction to Biostatistics. Freeman \& Co., New York.

Sólymos, P., R. Farkas, Z. Kemencei, B. Páll-Gergely, F. Vilisics, A Nagy, M. Kisfali and E. Hornung. 2009. Micro-habitat scale survey of land snails in dolines of the Alsó-hegy, Aggtelek National Park, Hungary. Mollusca 27 : 167-171.

Sulikowska-Drozd, A. and M. Horsák. 2007. Woodland mollusc communities along environmental gradients in the East Carpathians. Biologia Bratislava 62 : 201-209.

Taiti S. and Ferrara F. 1989. Biogeography and ecology of terrestrial isopods from Tuscany. Monit. Zool. Ital. (N.S.) Monogr. 4: 75101.

ter Braak, C.J.F. 1986. Canonical correspondence analysis: a new eigenvector technique for multivariate direct gradient analysis. Ecology 67: 1167-1179.

US EPA. 2004. SW 846 Ch. 6 Reference methodology: method 9045/D. Soil and waste $\mathrm{pH}$, Washington DC.

Valovirta, I. 1968. Land molluses in relation to acidity on hyperite hills in Central Finland. Ann. Zool. Fenn. 5: 245-253.

Received March 28, 2014

Revised June 22, November 17, 2014

Accepted March 25, 2015

\section{Electronic supplements}

Appendix 1. Occurrence and relative frequency of snail species in the three study areas.

Appendix 2. Shepard plot for NMDS ordination, internal similarity between areas based on Jaccard index, convex hull spider-web diagrams for similarity between areas and habitats based on presence/absence data and CCA diagrams for abundance data.

The file may be downloaded from www.akademiai.com. 